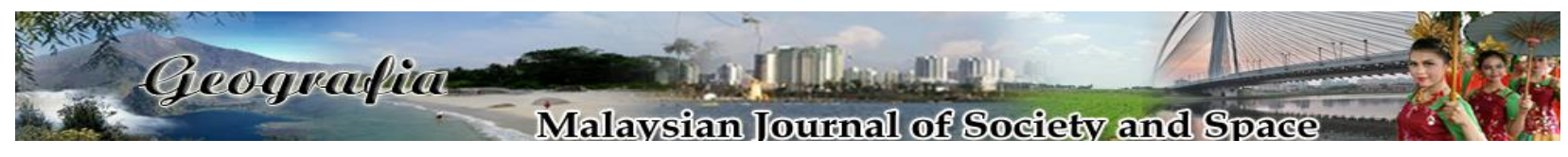

\title{
Silence and silencing: The case of trafficked women
}

\author{
Haezreena Begum Abdul Hamid \\ Institute of Criminology, School of Social \& Cultural Studies, Faculty of Humanities and Social Sciences, \\ Victoria University of Wellington, New Zealand
}

Correspondence: Haezreena Begum Abdul Hamid (email: haezreena@gmail.com)

Received: 30 April 2019; Accepted: 02 August 2019; Published: 22 August 2019

\begin{abstract}
This article builds on the agency theory and provides an analysis on how silence has been used as a tool to control trafficked women. The article argues that in many instances, traffickers and state institutions control women by dismissing their voice, or by depriving them from exercising their agency. In this respect, women who are vocal and verbalise their opinions are categorised as defiant and need to be controlled. Such beliefs stem from patriarchal influences that have been normalised and are deeply embedded in social structures, cultures, religions and social practices. To affirm these claims, the study conducted semi-structured interviews with 29 trafficked female migrants from seven different nationalities who were detained in a shelter in Kuala Lumpur, Malaysia. The study also interviewed 12 professionals that mainly consist of government officials to understand the implementation of the victim-protection policies. By providing an insight into women's experiences of sex-trafficking and state 'protection', the article discusses how the victim protection policies act to silence women by force. The findings of the study will demonstrate how silencing is used as a strategy to minimise harm and how women are silenced through language barriers. This article adds knowledge to the trafficking and victimization scholarship and expands the notion of silencing so that it can be more understandable and effective across cultures.
\end{abstract}

Keywords: agency, migrants, silencing, trafficked women, trafficking, victimization

\section{Introduction}

Human trafficking is a complex form of transnational crime that occurs within and across national borders (United Nations Office on Drugs and Crime, 2018). It involves the recruitment, transportation, transfer, harbouring or receipt of persons, by means of threat, force or other forms of coercion, of abduction, fraud, deception, of the abuse of power, a position of vulnerability, of the giving or receiving of payments or benefits to achieve the consent of a person having control over another person, for the purpose of exploitation (Saad \& Salman, 2014). According to 
Article 3A of the Protocol to Prevent, Suppress and Punish Trafficking in Persons, Especially Women and Children (Palermo Protocol), the three main elements for the identification of human trafficking offences are: (i) the act, which includes the recruitment, transportation, transfer, harbouring or receipt of persons; (ii) the 'means', which includes threat or use of force, coercion, abduction, fraud, deception, abuse of power or vulnerability, or giving payments or benefits to a person in control of the victim; and, (iii) the purpose, which includes exploiting the prostitution of others, sexual exploitation, forced labour, slavery or similar practices and the removal of organs (United Nations, 2003). Exploitation shall include, at a minimum, the exploitation of the prostitution of others or other forms of sexual exploitation, forced labour or services, slavery or practices similar to slavery, servitude or the removal of organs (Saad \& Salman, 2014).

Predominantly, the focus when examining human trafficking has been on women and children trafficked for the purpose of sexual exploitation (Segrave, Milivojevic, \& Pickering, 2009). This focus has been justified by the identification that victims of sexual exploitation are predominantly women and girls (United Nations Office on Drugs and Crime, 2018). However, the current knowledge based on this phenomenon is still exceptionally limited, particularly in Southeast Asian countries such as Malaysia. There is also a significant absence of women's voices and a shortage of empirical studies on trafficked women lived experiences (Agustin, 2010). Therefore, this article provides an insight into trafficked women's experiences and their responses in navigating the harms experienced throughout their migration period. It builds upon the agency theory which discusses how silencing is used by male-dominated structures to deny women's agency and marginalize women. It also demonstrates how women chose to remain silent as a strategy to minimise harm (Brennan, 2016). By providing an insight into women's trafficking experiences, the article develops a more nuanced account of victimisation and agency and unpacks the notion of 'silencing' to be more effective across cultures.

\section{Literature review}

\section{Background of sex work in Malaysia}

Sex work is criminalised and illegal in Malaysia. However, its geographic proximity to major trade and traffic routes, porous borders, and short distances from one state to another facilitates sex trafficking activities. In order to curb such activities, Malaysia acceded to the Palermo Protocol in 2009 and incorporated most of the provisions into its Anti-Trafficking in Persons and Smuggling of Migrant Act 2007 (ATIP). Under the ATIP, trafficked women are given an initial 21-day interim protection order (for suspected trafficking victims) and/or a subsequent 90-day protection order (for certified trafficking victims) from the court. The period of detention may also be extended by the court in order to facilitate the prosecution's case against the traffickers, since the prosecutors mainly rely on the cooperation and testimony of the women (U.S Department of State, 2016). Although the term 'Protection Order' is closely associated with 'welfarist language or rehabilitation and protection', women are actually held in conditions likened to semi-carceral institutions known as 'shelters' (Gallagher \& Pearson, 2010, p. 73) which is under the care of The Ministry of Women Affairs and Family Development.

Sheltered women are forced to wear uniforms, required to undergo multiple interviews and interrogation with government officials, held under strict surveillance, prohibited from 
communicating with anyone outside the shelter, and are deprived of medical, legal, translation and psychological services (U.S Department of State, 2014). They are required to adhere to all rules and regulations set by the state and are not given the opportunity to reject 'state protection'. In this context, social institutions impose laws and policies to limit women's voices and participation in their everyday lives. This includes limitation to their mobility (Lelea, 2012), freedom of movement and their ability to communicate with people outside of the shelter. Such acts visibly restrict, marginalize and victimize trafficked women.

The United States (U.S) has occasionally criticised the Malaysian government for its weak human rights protections, poor record on combatting human trafficking, and poor victim protection policies. The United States Department through its Office to Monitor and Combat Trafficking in Persons (USOMCT), undertakes a role to review trafficking internationally by assessing and ranking individual countries according to their policy responses and implementation outcomes, and publishing the findings in the TIP Report annually. The assessment and monitoring of efforts are measured against U.S-defined minimum standards for the elimination of trafficking (Saad \& Salman, 2014).

According to the tier-ranking, Tier One are countries that have made efforts to address the problem of human trafficking and complied with the United States Trafficked Victim Protection Act (TVPA) minimum standards. A Tier Two ranking indicates countries whose governments do not fully comply with the TVPA's minimum standards but are making significant efforts to do so. Tier Two Watchlist countries have not made significant progress to combat human trafficking, although they have made certain efforts to combat human trafficking. This includes the rising number of victims; low number of investigations, prosecution, and conviction; as well as poor standards of victim protection. Tier Three ranking is the lowest ranking which indicates countries whose governments do not fully comply with the minimum standards of the TVPA and are not making significant efforts to do so (U.S Department of State, 2018). Malaysia's past records can be seen below:

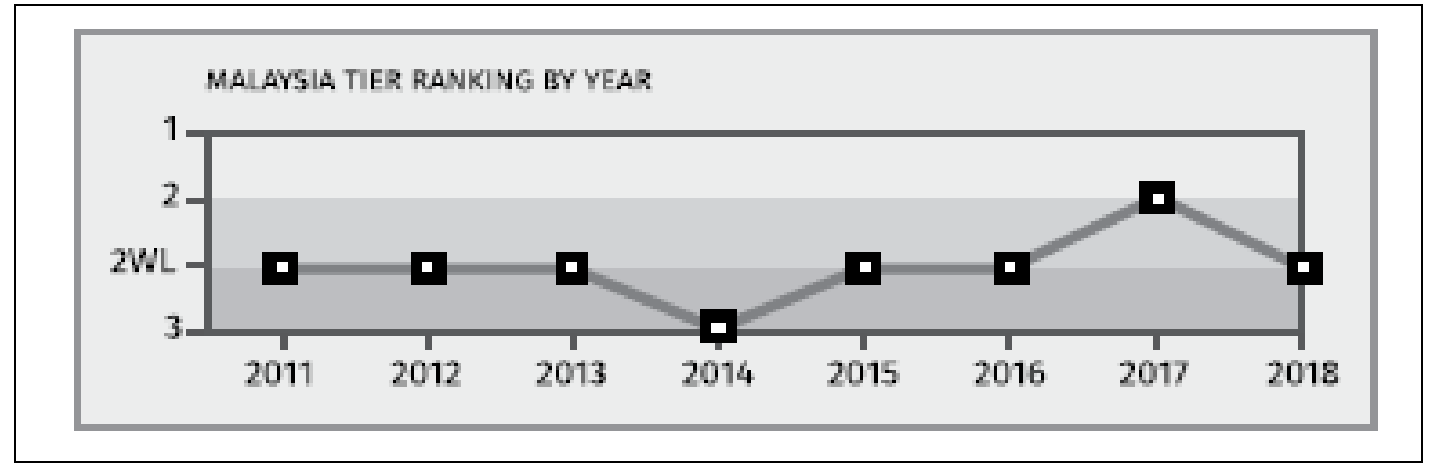

Source: U.S Department of State, 2018

Figure 1. Malaysia Tier Ranking by year

Figure 1 shows the U.S Tier ranking accorded to Malaysia from 2011 to 2018. The vertical line (left) shows the Tier ranking and the horizontal line shows the year. As seen in Figure 1, Malaysia has been placed at Tier Two Watchlist in 2018 for failing to make significant progress to improve its victim protection policies and to effectively combat human trafficking. In a bid to improve its victim protection policies, the Malaysian government amended the ATIP in late 2015 to allow trafficked persons to work and reside outside of the shelter. However, trafficked women 
are required to undergo a stringent risk assessment process, which involves security and medical examinations. They also need to obtain the approval from the Council of Anti-Trafficking in Persons and Migrant Smuggling (Council) (section 51A (2) ATIP). These approvals would be subject to the reports given by the Protection Officers (shelter officers) as well as the police. The bureaucracy involved in obtaining freedom of movement as well as a lack of interest in available work opportunities due to low wages, have resulted in a very low number of trafficked persons being granted the right to work (U.S Department of State, 2017). These complexities also suggest that legislation and policing are not carried out to protect women but are being used to control women. Although, opportunities were created to give women the chance to work and move freely, obstacles are being placed along their path, which makes it difficult for them to exercise their agency and live freely. The reluctance to grant trafficked women the right to freedom and choice stems from traditional patriarchal practices, which emphasises on women's silence and chastity.

\section{History of silence}

The history of silence is central to women's history (Solnit, 2017a). Voice, or the act of speaking out, is often identified in the gender and feminist literature, as one of the key conditions demonstrating women's agency and empowerment (Gilligan, 1982; Olsen, 2003). Therefore, denying or refusing a woman to speak also means denying her right to self-determination, participation, consent, dissent, live, participate, interpret and narrate (Solnit, 2017b). Therefore, silence is presumed to be a symbol of passivity and powerlessness (Mahoney, 1996). Mahoney (1996, p. 604) argues that 'those who are denied speech cannot make their experience known and thus cannot influence the course of their lives'. As Solnit (2017a, p. 1) contends:

"Quiet is to noise as silence is to communication. Silence can be construed as an act of intimidation or repression as it allows people to suffer without recourse, allows hypocrisies and lies to grow and flourish, and crimes to go unpunished. If voices are essential aspects of humanity, to be rendered voiceless is to be dehumanised or excluded from one's humanity".

The technique of silencing has been an effective strategy to subjugate and control women's bodies, speech, behaviour and activities. The silencing of women stems from age-old traditions, religion, cultural practices, stereotypes and attitudes about women and their role in the society (Ifechelobi, 2014). As the Holy Bible says in 1 Timothy chapter 2 verse 11-12, 'let a woman learn in quietness, in entire submissiveness. I allow no woman to teach or to have authority over men; she is to remain in quietness and keep silence' (Ifechelobi, 2014, p. 22). Similarly, in Islam, women's voices are considered aurah (restricted) and should be inaudible to men (Maududi, 1991). This injunction stems from the prohibition against stamping of feet which is to prevent women from revealing their ornaments they are wearing and also the fact that only men could make the call for Azan (the call to prayer) (Maududi, 1991). Consequently, women are 'shackled' by their own negative self-image and react with fear because of the dependency and their subordinate feelings towards men (Ifechelobi, 2014).

While the Western and Islamic influence on victimization has been widely acknowledged, the problems that arose due to historical, religious and cultural differences need to be expanded in the victimization and trafficking scholarship so that it can be more effective across cultures. In 
Malaysia for instance, women's voices, women's experiences, and women's realities have been mostly silent, silenced and marginalized by the dominant androcentric voice that validated men's superiority and control over women (Anwar, 2001). This silence is the result of restrictive state control over any discourse concerning the 'sensitive' issues of race and religion (Sani, 2008). Women who defy or reject these rules are seen as rejecting their heritage, their identity, and may even be accused of rejecting their religion (Othman, 2006). For example, Sisters in Islam (SIS) a non-governmental organization based in Malaysia who is noted for being vocal about women's rights, have been continuously berated and ridiculed by the Islamic Party PAS and Islamist activists who are mostly male (Othman, 2006). These groups constantly berate and accuse SIS of deviating from traditional Islamic teachings by spreading Western feminism values and liberal Islamic teachings on Muslims and the ummah (nation) (Othman, 2006). Scare tactics and continuous calls to ban SIS by Islamists are among the tactics used to silence 'lay' female Muslim scholars from engaging publicly in the discourse on Islam in Malaysia (Othman, 2006). Another recent example can be seen in the recent case of three female activists who were intimidated and harassed by The Selangor Islamic Religious Department (Jais) for a forum on 'dehijabing' (discarding of hijab) Malay women (Zurairi, 2019). The women activists claimed that it was undemocratic and an abuse of power to harass and intimidate women who spoke on issues affecting women, and organisers for having intellectual discussions about the requirement of wearing a hijab (Zurairi, 2019). This form of intimidation clearly shows how the state tried to control women, which has indirectly resulted in women's oppression in Malaysia (Zurairi, 2019).

Although silence may be seen as a form of weakness, silence can also be used as a powerful and active component of resistance because in many instances, the choice to publicly challenge the powerful is often extremely dangerous (Parpart, 2010). For trafficked women, the choice to publicly challenge the powerful (traffickers/employers) is often dangerous and may expose women to further harm (Parpart, 2010). This is because traffickers are usually individuals who control women and are capable of inflicting harm on women if they do not obey to his/her instructions. This includes: deprivation of psychological needs (e.g., no medical care; restricted food and water; limited sleep), or denial of right to privacy (e.g., overcrowded living and working conditions) all of which physically humiliate and degrade women, and induce physical exhaustion (Dando et al., 2016). Debt-bondage is also another technique used to control women. In this instance, traffickers create debts which are impossible to repay through accruing interest or additional fees (Pascual-Leone et al., 2017). These forms of violence are used with the intention of keeping women "in place"; in a subordinate position (Lelea, 2012).

In other instances, women are silenced through language barriers. This is particularly evident in cases of female migrants who have been trafficked to Malaysia and are unable to converse in either Malay or English. They are not provided with interpreters and are unable to express themselves clearly or understand the events that are happening around them. Thus, Du (2015) asserts that linguistic competence entails the ability to speak and the ability to understand. Without the ability to communicate and understand certain languages, women are displaced and denied the right or the opportunity to express themselves. They are not able to access medical, legal, and educational services, or denied appropriate care, which violates their rights as a trafficked victim (Clawson \& Dutch, 2008). Through these techniques, women are transformed into passive and obedient individuals and therefore, the likelihood of women escaping or disobeying their traffickers are minimal. As Win $(2004$, p. 76) concludes in her study on battered women (which can be applied to the case of trafficked women): 
"Any woman in a violent situation will tell you, there are no prizes for speaking out. If anything, you are branded a bad woman, or worse, you are violated all over again for daring to open your mouth”.

Besides preventing harm, women's silence can also be used as a method of communication to renegotiate harmful practices. According to the World Health Organization $(2002$, p. 95) study on health and violence:

"Most abused women are not passive victim, some women resist, others flee, while others attempt to keep the peace by giving in to their husbands' demands. What may seem to an outside observer to be a lack of positive response by the women may, in fact, be a calculated assessment of what is needed to survive in the marriage and to protect herself and her children".

Although silence can be seen as a form of empowerment and a survival strategy for women, silencing of women represents a form of violence and actors who seek to silence women are clearly in violation of women's fundamental rights.

\section{Methods and study area}

The study was conducted using semi-structured interviews with 29 trafficked women held in a shelter home for trafficked women, known as Rumah Perlindungan 5 in Kuala Lumpur. The interviews were held over a period of four weeks (15 April to 15 May 2016) and ethics approval was obtained from Victoria University to conduct this study. The reason for conducting the study in Malaysia is due to my ability to converse in several languages, such as Malay, English, Indonesian and several versions of Pidgin English. Given that the participants originated from Vietnam, Thailand, Indonesia, Laos and Myanmar, Bangladesh and Nigeria, a liberal and postcolonial feminist approach was taken to interview and conduct the study. The liberal feminist approach views men and women as equal, emphasizing the similarities between them and arguing that women can be as capable and as rational as men while post-colonial feminism acknowledges the class, race and religion of the participants which shapes their thinking and perspectives. The women were from different age group ranging from 18 to 44 years old and were rescued from massage parlours, brothels, entertainment centres and private dwellings throughout Peninsular Malaysia. All of them agreed to be interviewed and signed a Consent Form.

Questions were focused on: their life before migration; personal background; their reasons for migration; their exercise of agency (consent, choice, ability to voice their opinions); work experiences and problems they encountered; experiences of being 'rescued' by the enforcement officers from their workplace (or traffickers); any harms or injuries that they have experienced, and their thoughts for the future. However, for the purpose of this article, discussions will be focused on the reasons behind women's silence and the strategies used by traffickers and state authorities to silence women.

All the participants in this study are identified by a pseudonym to protect their identity. Twelve participants who could converse in Malay, Indonesian or English were directly interviewed by me while the remaining 17 who could only speak Thai or Vietnamese language 
were interviewed using interpreters. As well as this, 12 semi-structured interviews were conducted with the investigating officers, enforcement officers, protection officers, government officers, NGOs, and shelter officers across their workspaces (police headquarters, immigration headquarters, Rumah Perlindungan 5 and the Ministry of Women Affairs and Family Development). All of them could speak either Malay or English and they could converse well without the assistance of an interpreter.

Transcription was conducted through Nvivo Software and the data was coded and categorised into themes and sub-themes. Thematic analysis was used to search for preestablished concepts such as 'victimization', 'agency' and 'silencing'.

\section{Results and discussion}

\section{Silence and silencing of women during the trafficking period}

Despite the literature (as earlier discussed) and laws which advocate the freedom of speech for women, the voices of women, particularly those involved in sex work, are often silenced by their status as 'victims' or sexualised 'others' (Andrijasevic, 2007). In many instances, trafficked women are silenced through harmful ways such as being ridiculed, discriminated against, criminalised, stigmatised and treated as unworthy individuals. Although such forms of control are intended to transform women into passive and obedient individuals, the discussions in this article have so far shown that women have found ways to resist this imposition. In this instance, women often engage with their traffickers as a means to secure their wages and negotiate better working conditions

At the same time, silence is a powerful and active component of resistance. As Porter (2016) point outs, depending on motivation, silence may be a source of oppression, empowerment, pragmatism or agency. Therefore, some women may choose to remain silent for fear of their safety or that of their families. In this context, self-chosen silence is an agentic act. This includes learning to suppress feelings and negotiating better conditions for work. Such feelings became rather evident throughout the interviews when most of the women (participants) became emotional while narrating their life experiences. Many of them complained that their voices were not heard or dismissed by the traffickers, or the state officials. Thus, the findings of this study will demonstrate and confirm two main assertions: that silence can be used as a strategy to minimise harm and that language barriers are used as a strategy to silence and control trafficked women.

a. Silencing as a strategy to minimise harm

Nineteen women in this study complained about debt bondage, having their passports confiscated, and had limited movement. However, they opted to remain silent and did not challenge or argue with their traffickers/employers because they wanted to prevent any harmful outcomes. Informant 1 said:

"...I did not run away from the brothel because I do not have a passport and I am scared of being arrested. I entered Malaysia illegally through the jungle bordering Thai and Malaysia, guided by a middle-aged man. Although I disliked my job, I just 
kept quiet. I had to do it because I had no other choice. I needed to work to pay my debt and support my family. My mother is ill, and I have a 5-year-old daughter who both depend on me".

Informant 2 also had a similar story to tell. According to her:

"...I was offered by a friend work in a garment factory in Malaysia. She said that I could earn about USD1000 per month. However, I was shocked to discover that I had to work as a masseur in a massage parlour in Kuala Lumpur. I had no other choice but to comply with her instructions because I owed the massage parlour RM3000 for my travelling expenses. I continued working because I wanted to pay off my debts and support my family back home. The Captain [pimp] kept my passport, and I was not allowed to leave my workplace unaccompanied by him".

Cooperation by Informant 1 and 2 cooperation should not be viewed as compliance but as a strategy to minimise harm. It is also an example of limited agency given that both of them had limited choice and needed to work and pay off their debts. It also shows how they tried to overcome their emotions by prioritising their responsibilities as breadwinners of their families.

Informant 3 was deceived and tricked by her boyfriend to migrate to Malaysia on the pretext of pursuing her studies. However, she was forced to become a sex worker and earn money for her boyfriend and his new partner. She said:

“...I tried to run away from my boyfriend and seeked help from a Malay man, but he surrendered me back to my boyfriend. As a punishment, I was taken to an unknown house by five Nigerian men where I was stripped naked, beaten, sexually abused and videoed. One of them cut my finger and smeared my blood on a piece of white cloth and warned me that he had cast a curse upon me. Therefore, I should not attempt to run away again otherwise my family would be killed. After that incident, I did not try to argue with my boyfriend anymore. I just kept quiet and continued working. I was too scared to run away and kept working for my boyfriend until I was rescued by the police".

Informant 4 was tricked by her neighbour (who is also a work agent) into believing that she will be working as a waitress at a restaurant in Klang, However, she was forced by her trafficker to engage in sex work when she arrived in Malaysia. Her trafficker (a female) also threatened to beat her up if she did not obey to her instructions. According to Informant 4:

"...I refused to engage in sex work and tried to run away the night I arrived. The main grill was locked and Ibu [trafficker] hid the keys. When she realised that I wanted to run away, she gave me a stern warning and told me that she will beat me up if I ever tried to escape. She said that I owed her RM5000 for my travelling expenses and I need to serve at least eight to nine customers a day in return for food. I was scared for my life and just carried on working without any objections until the immigration officers rescued me". 
Based on the above, it is clear that women's behaviour and actions should be assessed based on the situation they are in and not interpreted solely on their actions or inaction. In this instance, women learn to navigate through coercive circumstances and engage strategies that could prevent them from experiencing further harm. This includes learning to seal off feelings and negotiating better conditions for work. In some cases, speaking out was not an option and silence was used as a systematic strategy to help women carry on with their lives (Bletzer, 2006). Therefore, it seems unfair to dismiss these choices as passivity and disempowerment as they are often the best (and sometimes the only) tactics available for building internal strength and for negotiating survival (Silber, 2005). The act of speaking out or rebelling against the traffickers or employers may be detrimental and harmful to women. Thus, women learnt to accept and live within their boundaries because of their determination to escape poverty and support their family.

\section{b. Silencing of women through language barrier}

The systematic denial of women's voices is also evident during state care and in the justice process. As earlier discussed, women are not given the opportunity to express themselves clearly due to the existing language barrier. Given that most women originate from foreign countries, they were unable to converse in the Malay or English language fluently. However, women were not provided with interpreters, which makes it difficult for them to express themselves. As in this study, all 29 participants complained of either not understanding what transpired during court proceedings or were not given the opportunity to speak during court trips. Informant 5 complained:

"I was brought to court but was not given the chance to talk. It was just the court officials and the police who were talking. After my case was over, I was told to return to the shelter."

In most cases, women were asked to sign a piece of paper without knowing the contents. Informant 6 said:

"...I was brought to court in a police truck. The police told me to wait at the long bench and he went in to do something. Later, he came out and asked me to sign a piece of paper. I signed it but I did not know what it was for".

According to Informant 7:

There was no interpreter in the courtroom. I had no idea what was going on, I only understood what was happening when the police said that I will be placed in the shelter for 21 days.

Similarly, Informant 8 complained about not understanding the language that was used in court:

“...They used Malay language in court and I did not understand what they said. They did not provide me with a Vietnamese interpreter. Nobody asked me anything”. 
The above examples show how women were affected by the language barrier. Not only were they not given the right to speak in court, they also had no idea of what transpired in court and what was said to them. The language barrier does not only occur in court but throughout the post-trafficking process. The services of a qualified interpreter would only be sought in cases where women are unable to express themselves through words, sign language or drawings. In this instance, individuals who are able to interpret and communicate in the women's language will be used to assist the Protection Officers in preparing their reports. However, these individuals may not be competent or fluent in the language. According to professional Informant 1:

"Communication is a big problem here. We use sign language and google translate at times. However, google translate does not help much. Therefore, the victim will tend to misunderstand our questions and will not answer us properly".

The above excerpt shows the communication barrier that exists in the shelter. Women were not provided with interpreters to enable them to understand and communicate. Instead, Google translate, sign language and drawings were amongst the modes of communication used for this purpose.

The above examples show how the language barrier has been used as a tool to disable women from understanding and speaking clearly. This can be seen through the fact that women were not given the chance to speak, informed of court processes or were aware of what transpired in court. The fact that many of them did not understand the Malay or English language used in court made it easier for the state to exert control over women and maintain their silence. By not providing women with interpreters, women struggle to understand the situation they are in and are effectively silenced from voicing out their opinions and thoughts. In this situation, women were forcefully deprived of their agency and their right to have their voices heard. This shows the lack of justice in the legal framework and the difficulties in accessing justice in Malaysia.

\section{Conclusion}

Women continue to be silenced throughout the trafficking and post-trafficking phase. Their voices are hardly heard in the media and they are always being spoken for by the police, immigration, or by politicians. The Ministry of Women's Affairs and Family Development (comprising of mainly females) who is responsible for 'protecting' trafficked women are equally liable in silencing women through its power relations. None of these versions address or sufficiently describes the situation as articulated by women themselves and thus, women's experiences of victimization are not properly understood by the state. The denial of rights and women's voices seek to silence women from voicing out their dissatisfaction, thus showing how the act of 'silencing' is conducted in the name of 'protection'. This increases and reinforces the oppression and marginalization of trafficked women. Despite the pressure and disadvantages women face, they are still able to comprehend and exercise their agency within the limited constraints. Issues of language barriers have to be addressed in order to allow women the ability to communicate and understand the situation they are confronted with. This would ease the investigation process and provide women with the necessary relief they need. 


\section{Acknowledgement}

The writer wishes to express her gratitude to the reviewers for their constructive comments and feedback of an earlier version of this paper. While every effort has been made by the writer to ensure accuracy and objectivity in the revised version, any remaining mistakes are unintentional, and any weaknesses are the responsibility of the writer.

\section{References}

Agustin, L.M. (2010). The (crying) need for different kinds of research. In Ditmore, M., Levy, A., \& Willman, A. (Eds.), Sex work matters (pp. 23-27). London, Zed Books.

Andrijasevic, R. (2007). Beautiful dead bodies: gender, migration and representation in antitrafficking campaigns. Feminist Review, 86(1), 24-44.

Anwar, Z. (2001). What Islam, whose Islam? Sisters in Islam and the struggle for women's rights. In Hefner, R.W. (Ed.), The politics of multiculturalism: Pluralism and citizenship in Malaysia, Singapore, and Indonesia. Honolulu, University of Hawai'i Press.

Bletzer, K.V. (2006). A voice for every woman and the travesties of war. Violence Against Women, 12(7), 700-705.

Brennan, D. (2016). Life interrupted: Trafficking into forced labor in the United States. Durham, North Carolina, Duke University Press.

Clawson, H.J., \& Dutch, N. (2008). Addressing the needs of victims of human trafficking: Challenges, barriers, and promising practices. Retrieved from http://humantraffickinghotline.org

Dando, C.J., Walsh, D., \& Brierley, R. (2016). Perceptions of psychological coercion and human trafficking in the west midlands of England: Beginning to know the unknown. PLos One, 11(5), 1-13.

$\mathrm{Du}, \mathrm{B}$. (2015). The silenced interpreter: A case study of language and ideology in the Chinese Criminal Court. International Journal for the Semiotics of Law, 28(3), 507-524.

Gallagher, A., \& Pearson, E. (2010). The high cost of freedom: A legal and policy analysis of shelter detention for victims of trafficking. Human Rights Quarterly, 32(1), 73-114.

Gilligan, C. (1982). In a different voice: psychological theory and women's development. Cambridge, Harvard University Press.

Ifechelobi, J.N. (2014). Feminism: Silence and voicelessness as tools of patriarchy in chimamanda adichie's purple hibiscus. African Research Review, 8(4), 17-27.

Lelea, M.A. (2012). Mapping progress and challenges for women's empowerment in the Global South. Geografia - Malaysian Journal of Society and Space, 8(1), 60-73.

Mahoney, M.A. (1996). The problem of silence in feminist psychology. Feminist Studies, 22(3), 603-625.

Maududi, A. (1991). Purdah and the status of women in Islam. Lahore, Islamic Publications.

Olsen, T. (2003). Silences. New York, Feminist Press at the City University of New York.

Othman, N. (2006). Muslim women and the challenge of Islamic fundamentalism/extremism: An overview of Southeast Asian Muslim women's struggle for human rights and gender equality. Women's Studies International Forum, 29(4), 339 - 353. 
Parpart, J. L. (2010). Choosing silence: rethinking voice, agency and women's empowerment. In Ryan-Flood, R., \& Gill, R. (Eds.), Secrecy and silence in the research process: Feminist reflections. Oxon, UK, Routledge.

Pascual-Leone, A., Kim, J., \& Morrison, O.-P. (2017). Working with victims of human trafficking. J. Contemp. Psychotherapy, 47(1), 51-59.

Porter, E. (2016). Gendered narratives: Stories and silences in transitional justice. Human Rights Review, 17(1), 35-50.

Saad, S., \& Salman, A. (2014). Government policy and the challenge of eradicating human trafficking in Malaysia. Geografia - Malaysian Journal of Society and Space, 10(6), 66-74.

Sani, M.A.M. (2008). Freedom of speech and democracy in Malaysia. Asian Journal of Political Science, 16(1), 85-104.

Segrave, M., Milivojevic, S., \& Pickering, S. (2009). Sex trafficking: International context and response. Devon, Willan Publishing.

Silber, I.C. (2005). Mothers/Fighters/Citizens: Violence and disillusionment in Post-War El Salvador. In D'Cruze, S., \& Rao, A. (Eds.), Violence, vulnerability and embodiment: Gender and history (pp. 67-93). Oxford, Blackwell.

Solnit, R. (2017a). The mother of all questions: Further feminisms. London, Grant Books.

Solnit, R. (2017b). Silence and powerlessness go hand in hand - women's voices must be heard. Retrieved from https://www.theguardian.com

U.S Department of State. (2014). Malaysia: Office to monitor and combat trafficking in persons: 2014 Trafficking in Persons Report: Tier 3. Retrieved from http://www.state.gov

U.S Department of State. (2016). Trafficking in Persons Report 2016 - Malaysia. Retrieved from https://www.state.gov

U.S Department of State. (2017). Malaysia: Office to Monitor and Combat Trafficking in Persons: 2017 Trafficking in Persons Report: Tier 2. Retrieved from https://www.state.gov

U.S Department of State. (2018). Trafficking in Persons Report 2018. Retrieved from https://www.state.gov

United Nations. (2003). Protocol to Prevent, Suppress and Punish Trafficking in Persons, Especially Women and Children (Palermo Protocol) (entered into force on 25 Dec 2003). Paper presented at the Protocol to Prevent, Suppress and Punish Trafficking in Persons, Especially Women and Children, Geneva.

United Nations Office on Drugs and Crime. (2018). Human trafficking. Retrieved from https://www.unodc.org

Win, E.J. (2004). Open letter to Nkosazana Dlamini-Zuma and other women in the South African Cabinet. Feminist Africa, 3(1), 74-76.

World Health Organization. (2002). World report on violence and health. Geneva, World Health Organization.

Zurairi, A. (2019). 'Dehijabing' forum panelists acuse Jais of harassing, intimidating female activists. Retrieved from https://www.malaymail.com 